\title{
Prevalence of fibromyalgia in medical students and its association with lifestyle factors - a cross-sectional study
}

\author{
Agastya Patel $^{1}$ ID, Ahmed Al-Saffar ${ }^{1}{ }^{\text {ID }}$, Manvi Sharma ${ }^{1}$ ID, Anna Masiak ${ }^{2}$ ID , \\ Zbigniew Zdrojewski ${ }^{2}$ ID
}

${ }^{1}$ Student Scientific Circle of Clinical Rheumatology, Department of Internal Diseases, Connective Tissue Disorders and Geriatrics, Medical University of Gdansk, Poland

${ }^{2}$ Department of Internal Diseases, Connective Tissue Disorders and Geriatrics, Medical University of Gdansk, Poland

\begin{abstract}
Objectives: Fibromyalgia (FM) is a chronic widespread pain syndrome, known to be associated with several other symptoms. Chronic stress is suspected to be a contributing factor in the pathogenesis of FM. It is known that medical students are under a constant state of stress originating from personal and social expectations. The aim of the study was to assess the prevalence of FM in this population and identify lifestyle parameters influencing FM severity.

Material and methods: An online survey of first- and final-year medical students was conducted using the ACR modified 2016 criteria and FANTASTIC checklist. The survey acquired demographic information such as age, gender, year, and division of studies. A subgroup analysis based on gender, year of studies, and division of studies was performed.

Results: 439 medical students ( $71 \%$ females) completed the survey. The overall prevalence of FM in our cohort was $10.48 \%$. The ratio of females to males was $3: 1$. A significant negative correlation between better quality of lifestyle and worse FM severity was observed in all subgroups. The "insight", "sleep and stress", "behavior" and "career" domains of lifestyle were found to have a significant negative correlation with FM severity on univariate analysis.

Conclusions: The prevalence of FM in medical students seems to be considerably higher than in the general population. Chronic stress levels, sleep problems, social support, and behavior seem to be the major factors influencing FM severity in this population. Our findings suggest that medical students must be considered a "high-risk" group for FM, and hence must be identified, educated, and managed accordingly. It is, therefore, important for medical universities to implement programs educating students about FM, the importance of a healthy lifestyle, and stress coping strategies, while also making systemic changes to curb stressors in medical training.
\end{abstract}

Key words: epidemiological studies, fibromyalgia, medical students, lifestyle factors.

\section{Introduction}

Fibromyalgia (FM) is a complex, centralized pain syndrome characterized by chronic widespread musculoskeletal pain and fatigue [1]. It may be accompanied by several other symptoms such as chronic headaches, paresthesia, sleep disturbances, mood and cognitive disorders, psychiatric symptoms (depression, anxiety), and visceral pain [1, 2]. The global prevalence of FM is appro- ximately $2 \%$, ranging from 0.2 to $6.6 \%$ depending on the diagnostic criteria used [3-6]. The diagnosis of FM is on average three times more common in females than in males, with prevalence increasing with age $[3,7]$.

The pathogenesis of FM is probably multifactorial, however, the mechanisms still remain largely unclear. Some evidence suggests that chronic stress is one of the factors involved in this complicated process [7]. A history

Address for correspondence:

Agastya Patel, Student Scientific Circle of Clinical Rheumatology, Department of Internal Diseases, Connective Tissue Disorders and Geriatrics, Medical University of Gdansk, 7 Dębinki St., 80-211 Gdansk, Poland, e-mail: agastyap24@gumed.edu.pl

Submitted: 24.03.2021; Accepted: 12.05.2021 
of psychological distress such as negative life experiences (physical or sexual abuse, work and traffic accidents) and environmental stressors (overactive lifestyle, demanding working conditions) appear to be triggers for FM [8-11]. Several studies have demonstrated hypothalamic-pituitary-adrenal axis dysregulation and neurochemical alterations in FM patients, similar to those seen in individuals with chronic stress $[12,13]$.

It is a universally accepted notion that medical studies are challenging. Medical students are under a constant state of stress originating from the highly competitive environment, personal and parental expectations, minimal leisure time, decisions regarding future specialty choices and even developing compassion fatigue $[14,15]$. This has resulted in a considerable portion of medical students reporting being burned out or suffering from psychiatric and sleep disorders. Recent metaanalyses have shown that approximately 1 in 3 medical students, globally, suffers from depression, anxiety, poor sleep quality or psychological distress [16-18].

Such chronic exposure to stress also presents "fertile" grounds for developing other chronic illnesses such as FM. Considering the association of psychiatric, sleep disorders and chronic stress with FM, it may be speculated that a substantial proportion of medical students suffer from or are at risk of developing FM in the future. However, there is limited data on the prevalence of FM in this specific cohort. Additionally, there is no evidence on how different aspects of a medical student's lifestyle influences the diagnosis and severity of FM.

In this cross-sectional study, we provide a comprehensive insight into the prevalence of FM in medical students and stratify it based on gender, year of study and origin of students. The secondary objective of the study is to examine potential associations between lifestyle factors and severity of FM in medical students.

\section{Methods and materials Participant recruitment}

The first and final $\left(5^{\text {th }}-6^{\text {th }}\right)$ year medical students at the Medical University of Gdansk (MUG) were recruited online to take part in this study. A survey consisting of demographic questions (age, gender, year of studies), the American College of Rheumatology (ACR) modified 2016 criteria and the FANTASTIC lifestyle checklist (FLC) questions was prepared in English. At MUG, medical studies are provided in English as well as Polish; therefore students were dichotomized in two categories as English Division (ED) and Polish Division (PD) students. To avoid misinterpretation of the survey, the questions were translated into Polish by two authors (AA, AM) (with professional proficiency in English and Polish).
After comparing the translations, a final Polish version of the survey was prepared.

The distribution of students as ED and PD enabled an analysis of FM prevalence in medical students from a global perspective. The PD group is composed of $98 \%$ Polish origin students while the ED group is a mixture of diverse origins, with the majority of students coming from different European, Asian and African countries. The English and Polish versions were sent to all first and final $\left(5^{\text {th }}-6^{\text {th }}\right)$ year ED and PD medical students, respectively, via the MUG emailing platform and through several university social media groups. The survey was sent on three different occasions, each separated by a period of four weeks. During the second and third send out, the students who had already completed the survey were asked not to complete it again.

The study was approved by the Independent Bioethics Committee for Scientific Research at the Medical University of Gdansk, Poland.

\section{ACR modified 2016 criteria and FANTASTIC lifestyle checklist}

In order to determine the prevalence of FM, the ACR modified 2016 criteria for diagnosis of FM were utilized [19]. It comprises of two components: the Widespread Pain Index (WPI) and the Symptom Severity Scale (SSS) score. The Widespread Pain Index is calculated based on the number of body areas in which the patient experienced pain over the last week. The SSS assesses the severity of common FM symptoms such as fatigue, waking unrefreshed and cognitive symptoms experienced over the previous week, and headaches, abdominal pain/cramps and depression experienced over the last 6 months. The summation of WPI and SSS results in a Fibromyalgia severity scale (FSS), which ranges from 0 to 31 points.

The respondent was considered positive for FM if the following three conditions were met:

1) $W P I \geq 7$ out of 9 body areas and SSS $\geq 5$ OR WPI $=4-6$ and SSS $\geq 9$ (the total FSS score must be $\geq 12$ points),

2) has generalized pain (pain in $\geq 4$ out of 5 body regions, excluding jaw, chest and abdominal pain),

3) has symptoms for at least 3 months.

The FLC was utilized to assess the lifestyle of the medical students. It is a 25-item questionnaire assessing social, emotional, physical and professional aspects of an individual's lifestyle [20]. It has been validated for use in several different populations and age groups $[21,22]$. It is subdivided into 9 domains using the acronym FANTASTIC ("Family and friends", "activity", "nutrition", "tobacco and toxins", "alcohol”, "sleep and stress", "behavior", "insight" and "career"). Each item is scored on a 4-point Likert scale, resulting in a maximum total 
score of 100 points. Based on the total score, the lifestyle quality can be categorized as needs improvement (0-34 points), fair (35-54 points), good (55-69 points), very good (70-84 points) and excellent (85-100 points). The Cronbach's $\alpha$ for FLC in our cohort was 0.827.

\section{Statistical analysis}

The assumption of normality was tested using the Shapiro-Wilk test. Continuous variables were analyzed using the Mann-Whitney $U$ test and reported as median (interquartile range - IQR). Categorical data were analyzed using Fisher's exact test and chi-square test, depending on the sample size analyzed and reported as number (percentage). If the sample size of categorical data was zero, the two consecutive groups were combined to allow analysis using the chi-square test. Significance of the results was assumed if the p-value (twotailed) was less than 0.05. The strength of association between FSS and FLC domain scores was assessed by Spearman's rank correlation test.

The data were computed and analyzed using Microsoft Excel 16.0.1 and GraphPad Prism 8.0.1.

\section{Results}

A total of 1437 first and final-year medical students at the MUG were asked to complete the online survey. Of these, 439 (31\% response rate) students completed the survey and were included in the analysis. The final cohort included 313 (71\%) females and 126 (29\%) males. The median age of the cohort was 21 (19-24) years. The demographic characteristics of the study group are summarized in Table I.

The prevalence of FM in our cohort was $10.48 \%$, with 46 out of the 439 students meeting the ACR modified 2016 criteria for the diagnosis of FM (Table II). The median FSS score for the entire cohort was 8 (6-12) points (Table III).

The lifestyle of the students was graded as "needs improvement" (0.23\%), "fair" (10.48\%), "good" (40.09\%), "very good" (44.87\%), and "excellent" (4.33\%), according to the FLC. The median FLC score was 69 (61-76) points (Table III). A negative correlation was observed between FSS and total FLC score (Figure 1). Similarly, a negative correlation between FSS and all FLC domains (except "alcohol" and "tobacco and toxins") was observed. "Insight", "sleep and stress", "behavior" and "career" were the domains with the strongest negative correlation with FSS (Table IV).

\section{Males versus females}

The demographic characteristics of male and female students in terms of age $(p=0.48)$ and year of study $(p=0.14)$ were similar.
Table I. Demographic characteristics of the study group

\begin{tabular}{|lc|}
\hline Parameters & $n$ \\
\hline Age, years [median (IQR)] & $21(19-24)$ \\
\hline Gender, $n(\%)$ & $126(28.7)$ \\
\hline Male & $313(71.3)$ \\
\hline Female & $246(56.0)$ \\
\hline Year of study, $n(\%)$ & $193(44.0)$ \\
\hline First year & $302(68.8)$ \\
\hline Final year & $137(31.2)$ \\
\hline Division of study, $n(\%)$ & \\
\hline Polish Division & \\
\hline English Division & \\
\hline
\end{tabular}

Table II. Prevalence rates of medical students meeting the ACR 2016 criteria for fibromyalgia among 439 medical students in the study group

\begin{tabular}{|lccc|}
\hline Groups & $\begin{array}{c}\text { Polish Division } \\
n(\%)\end{array}$ & $\begin{array}{c}\text { English Division } \\
n(\%)\end{array}$ & $\begin{array}{c}\text { Overall } \\
n(\%)\end{array}$ \\
\hline Overall & $31(10.26)$ & $15(10.95)$ & $46(10.48)$ \\
\hline $\begin{array}{l}\text { First year } \\
\text { Male }\end{array}$ & $15(8.52)$ & $9(12.86)$ & $24(9.76)$ \\
\hline Female & $13(10.23)$ & $5(13.79)$ & $6(7.70)$ \\
\hline Final year & $16(12.70)$ & $6(8.96)$ & $22(11.40)$ \\
\hline Male & $2(10.53)$ & $2(6.89)$ & $4(8.30)$ \\
\hline Female & $14(13.72)$ & $4(9.30)$ & $18(12.40)$ \\
\hline
\end{tabular}

The prevalence of FM in females was $11.5 \%$ and in males was 7.94\% (Table II). The median FSS was significantly higher in females compared to males [9 (6-12) vs. 7 (4-11), $p<0.001$ ] (Table III). Similarly, it was significantly higher in first-year and final-year females than their male counterparts (Table III).

The distribution of lifestyle assessment categories for females and males is depicted in Figure 2A and $2 \mathrm{~B}$, respectively. Similarly to FSS score, the median FLC score was also significantly better in females compared to males [71 (63-77) vs. 66 (57.75-73), $p<0.001$ ] (Table III). There was an inverse correlation between FSS and FLC score, irrespective of gender and year of study $(p<0.001)$ (Table III). In univariate analysis, all domains of the FLC were negatively correlated with FSS score in the female subgroup (Table IV), while in the male subgroup, all domains except for "tobacco and toxins" and "alcohol" were negatively correlated with FSS score (Table IV).

\section{First-year versus final-year students}

Our cohort comprised of $50.04 \%$ first-year and $43.96 \%$ final-year medical students. As expected, the final- 
Table III. Fibromyalgia severity scale (FSS) and Fantastic lifestyle checklist (FLC) scores, and data on correlation analysis between the two, stratified according to gender, year of study and division of study. Values are reported as median (IQR)

\begin{tabular}{|c|c|c|c|c|c|c|}
\hline Groups & FSS & $p$-value & $\mathrm{FLC}$ & $p$-value & $R$ coefficient & $p$-value \\
\hline Overall & $8(6-12)$ & - & $69(61-76)$ & - & -0.5112 & $<0.001$ \\
\hline Male & $7(4-11)$ & \multirow[t]{2}{*}{$<0.001$} & $66(57.75-73)$ & \multirow[t]{2}{*}{$<0.001$} & -0.6101 & $<0.001$ \\
\hline Female & $9(6-12)$ & & $71(6-77)$ & & -0.5496 & $<0.001$ \\
\hline Male - first year & $7(4-12)$ & \multirow[t]{2}{*}{0.02} & $63(55-73)$ & \multirow[t]{2}{*}{0.02} & -0.5918 & $<0.001$ \\
\hline Female - first year & $9(6-13)$ & & $67(61-75)$ & & -0.5846 & $<0.001$ \\
\hline Male - final year & $6(3.25-8)$ & \multirow[t]{2}{*}{0.001} & $68(63-75.75)$ & \multirow[t]{2}{*}{0.01} & -0.5737 & $<0.001$ \\
\hline Female - final year & $8(6-12)$ & & $73(67-79)$ & & -0.4881 & $<0.001$ \\
\hline First year & $9(6-12)$ & \multirow[t]{2}{*}{0.07} & $66(58-74)$ & \multirow[t]{2}{*}{$<0.001$} & -0.5464 & $<0.001$ \\
\hline Final year & $8(5-12)$ & & $72(65-78)$ & & -0.4371 & $<0.001$ \\
\hline Polish Division & $9(6-12)$ & \multirow[t]{2}{*}{0.01} & $69(61-75.5)$ & \multirow[t]{2}{*}{0.64} & -0.4780 & $<0.001$ \\
\hline English Division & $7(4-11)$ & & $69(62-77)$ & & -0.5724 & $<0.001$ \\
\hline
\end{tabular}

year students were significantly older than the first-year students [20 (19-20) vs. $24(24-25)$ years, $p<0.001]$. The distribution of males and females in the first-year and final-year subgroups was similar.

The prevalence of FM was $9.76 \%$ and $11.4 \%$ in firstyear and final-year students, respectively (Table II). The FSS score was similar between the two subgroups [9 (6-12) vs. 8 (5-12), $p=0.07$ ] (Table III). The categorization of FLC lifestyle assessment for first and final-year students is presented in Figure 2C. The first-year students had a significantly lower FLC score than final-year students [66 (58-74) vs. 72 (65-78), $p<0.001$ ] (Table III). There was an inverse correlation between FSS and FLC scores for both subgroups (Table III). For first-year students, all FLC domains except "tobacco and toxins" and

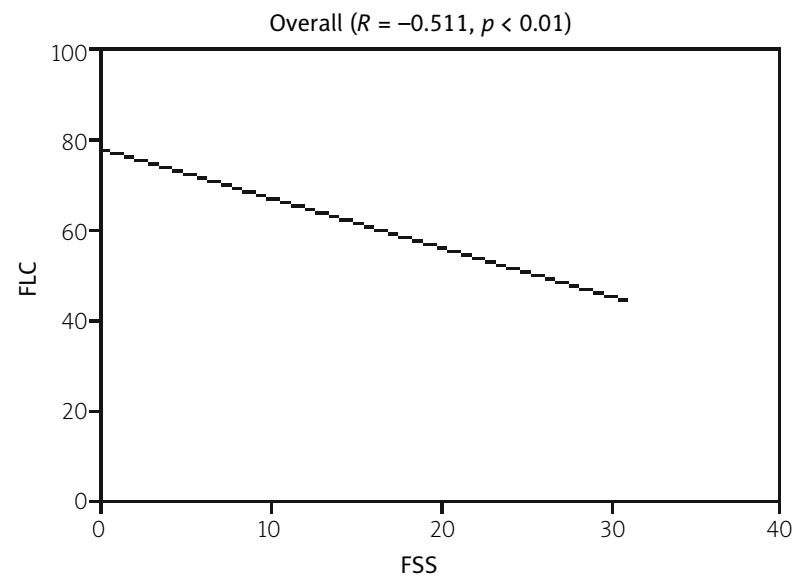

Fig. 1. Graph showing significant negative correlation between Fibromyalgia severity scale (FSS) and FANTASTIC lifestyle checklist (FLC) for the entire study cohort. "alcohol" were negatively correlated with FSS score. For final-year students, all FLC domains except for "nutrition", "activity", "tobacco and toxins" and "alcohol" were negatively correlated with FSS score. "Insight", "sleep and stress", "behavior" and "career" were the FLC domains with the greatest negative influence on FSS score for both subgroups (Table IV).

\section{Polish Division versus English Division}

302 (68.8\%) and 137 (31.2\%) of the students included in the analysis belonged to the PD and ED section of medical studies at the MUG. The ED subgroup comprised of significantly significantly more male students ( $39 \%$ vs. $24 \%, p=0.002$ ) than PD. The ED students were also significantly older than PD students [23 (20-25) vs. 20 (19-24), $p<0.001]$.

The prevalence of FM was similar between PD and ED students (10.26\% vs. 10.95\%) (Table II). The proportions based on gender and year of students are provided in Table II. The FSS score was significantly higher in PD students compared to ED students [9 (6-12) vs. 7 (4-11), $p=0.01$ ] while the FLC score was similar between them $(p=0.64)$ (Table III). The distribution of lifestyle assessment scores for PD and ED students is presented in Figure 2D. The FSS and FLC scores of both PD and ED students were found to have a significant negative correlation (Table III). On univariate correlation analysis, all FLC domains except for "alcohol" and "tobacco and toxins" were found to have a negative correlation with FSS score for both PD and ED subgroups (Table IV).

\section{Discussion}

A detailed report of FM prevalence in medical students in terms of gender, year of study and origin of stu- 


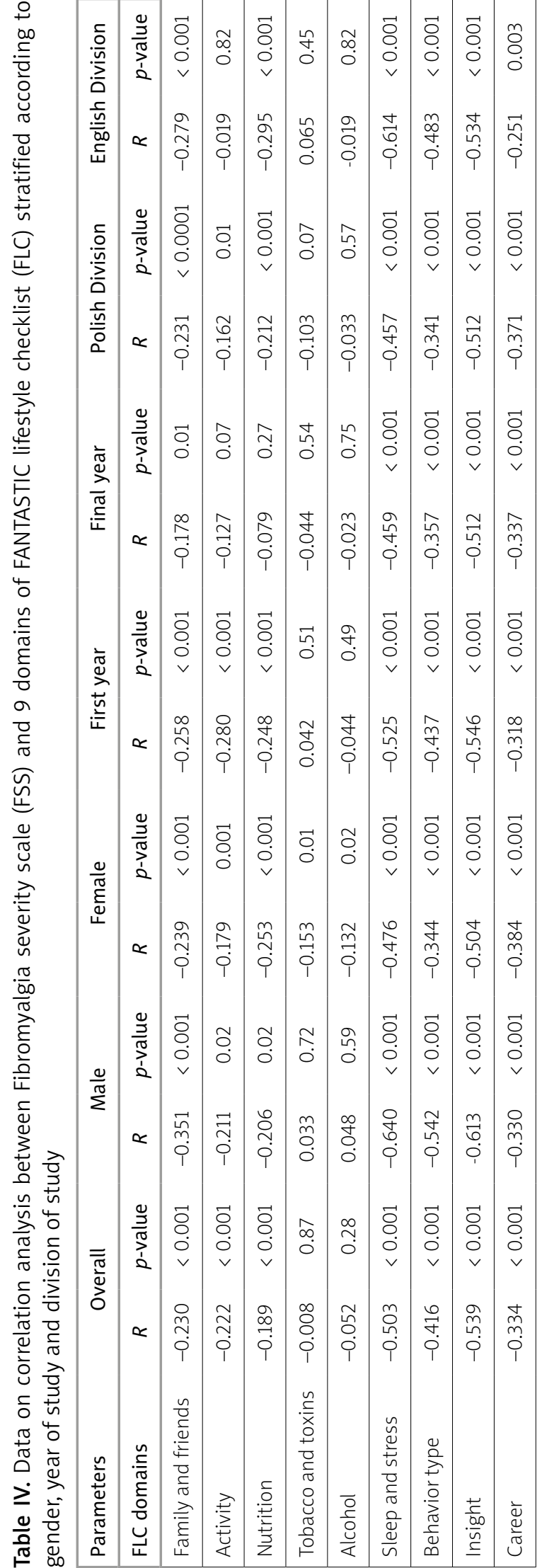

dents has not been previously reported. In our cohort, the overall prevalence of FM was $10.48 \%$, which is considerably higher than in the general population (approximately 2\%) [3]. However, similarly to the general population, FM was more common in female students and in older (final year) students. The ratio of female to male students meeting the ACR modified 2016 criteria was $3: 1$, which is also comparable to the general population [7]. Previous studies have provided some evidence that there may be ethnic differences in the prevalence of FM $[23,24]$. However, in our cohort, origin of the students did not seem to influence the prevalence of FM.

Contrary to our results, the few studies published on FM in health professionals and medical students have reported prevalence rates resembling those of the general population. A survey of 539 Japanese hospital workers revealed an overall FM prevalence of $1.48 \%$, while another study including 306 Turkish medical students found the prevalence to be $2 \%[25,26]$. These studies utilized the ACR 1990 criteria for classification of FM to identify positive subjects.

On the other hand, congruent to our results, Omair et al. [27] reported high prevalence in Saudi Arabian residents and fellows - 6\%, 8.2\% and $11.6 \%$ using three different questionnaires: the FM Rapid Screening Tool, FM Screening tool and FM Epidemiological Study Screening Questionnaire, respectively. The differences in ethnicity and specific medicine-related cohort studied might provide one explanation for the variation in prevalence rates across the mentioned studies. Additionally, the different tools and criteria used to diagnose FM may have influenced prevalence rates. Jones et al. [6] stated that the modified ACR 2010 criteria resulted in higher prevalence rates than the historic ACR 1990 criteria. The ACR modified 2016 criteria presented minor changes and clarification to the modified ACR 2010 criteria. Hence, it is possible that the differences between ACR 1990 and ACR modified 2016 criteria explain the variation in FM prevalence in medical students of our study and that of Eyigor et al. [26].

To our knowledge, no previous research has investigated the impact of lifestyle factors on FM in medical students. Our study demonstrated that students with a better quality of lifestyle (higher FLC score) were more likely to have less severe FM than those with a poor lifestyle. Our analysis found the following FLC domains to be negatively correlated with FM severity: "Sleep and Stress", "Insight", "Behavior", "Career" and "Family and Friends", regardless of the gender, year of study or origin of students. Interestingly, the use of tobacco, drugs and alcohol did not appear to influence FM severity in any subgroup, except for in females. This is contradictory to previous studies researching the impact of tobacco and 
A

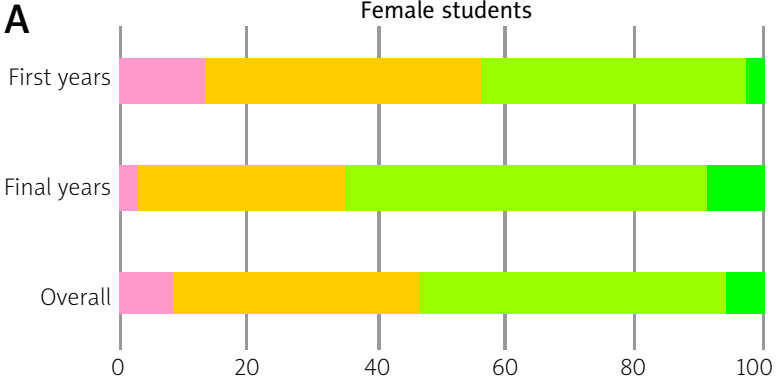

(\%)

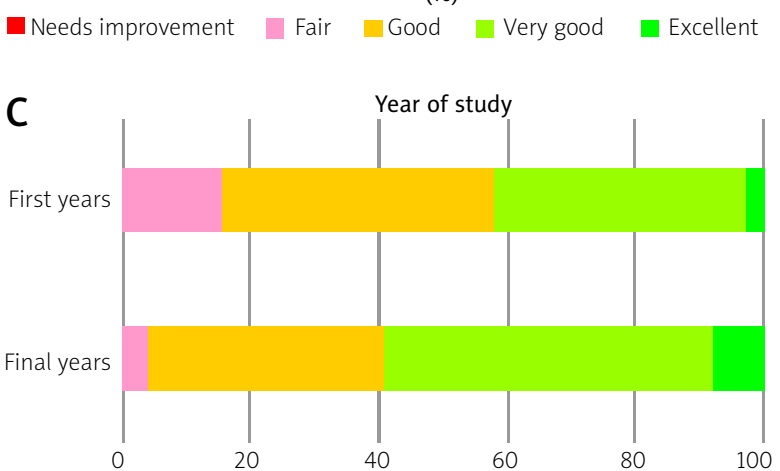

(\%)

Needs improvement Fair Good Very good Excellent

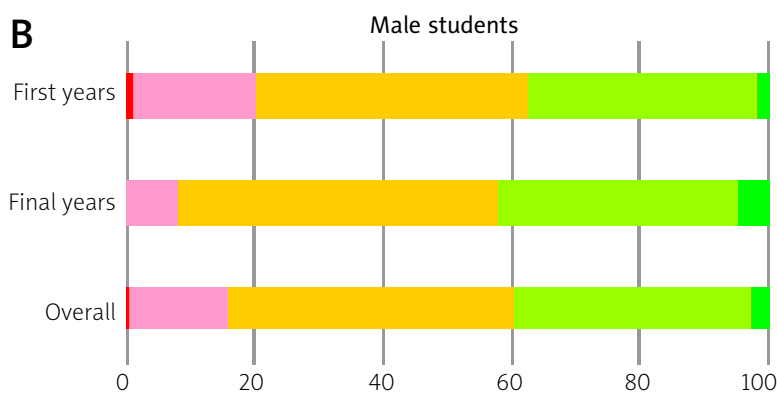

(\%)

Needs improvement $\quad$ Fair Good Very good Excellent

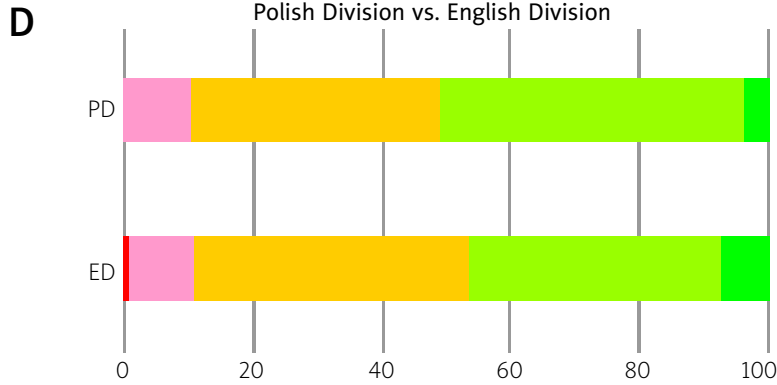

(\%)

Needs improvement Fair Good Very good Excellent

Fig. 2. Lifestyle assessment according to FANTASTIC lifestyle checklist grades. Female students (A) and male students (B), according to the year of study and combined. First-year and final-year students (C), and Polish Division and English Division students (D).

alcohol use in FM patients. Ge et al. [28] found that tobacco smokers reported higher severity of FM and related symptoms, while another study found that moderate alcohol consumption improved quality of life and symptom severity of FM patients [29].

As a solution to the issue at hand, medical universities must consider implementation of psychoeducational and behavioral therapy training courses to appropriately assist susceptible students. It is essential to educate students on the complex nature of FM, and the importance of sleep hygiene, nutrition, graded exercise and relaxation techniques [30, 31]. Medical students must have access to resilience and mindfulness training with special emphasis on stress-coping strategies. These interventions will assist medical students to deal with the environmental and personal stressors prevalent in medical education and professional practice [32-34]. Furthermore, there is a need to improve medical student's knowledge regarding FM, especially since evidence suggests that they lack appropriate knowledge of this disease [35]. Patient education is a crucial aspect of FM management; therefore, improving students' understanding of the disease will not only help them recognize and improve their own symptoms and lifestyle, but also benefit their future patients [36].

Additionally, there is a need to make systemic changes in medical education to improve student mental health and reduce stressors pertaining to issues of studentteacher relationship, demanding curriculum and expectations, difficulty and frequency of examinations and the overall environment of medical universities [37, 38]. Slavin et al. [38] suggested potential ways to reduce stress levels in the early period of medical studies such as implementing a pass/fail grading system, reducing curriculum time and detailedness, and introducing mandatory resilience/mindfulness training to the curriculum. Through such interventions, the authors have noted a significant reduction in student-reported stress levels and associated side effects at their university.

There is also a need to develop a safe, supportive and non-threatening environment within the framework of medical universities by eliminating mental health stigma, promoting mentoring programs (via academic advisors and peers), psychological counselling and encouraging student-tutor interaction to identify, fix and reduce prevalent stressors $[39,40]$.

\section{Limitations of the study}

First, the response rate to our survey was 31\% resulting in a small sample size. However, the response rates of first-year, final-year, PD and ED students were similar; thus our cohort manages to provide a reliable represen- 
tation of our study population. Second, the cross-sectional study design does not enable an assessment of FM risk in medical students. Third, the students were considered to have FM solely based on an online survey, without a medical examination.

Regardless of these limitations, our study is the first research which provides a comprehensive insight into the prevalence of FM in medical students and characterize the influence of lifestyle factors on FM severity.

\section{Conclusions}

Our findings suggest that the prevalence of FM in medical students is considerably higher in comparison to the general population. Therefore, it is important to recognize them as a potentially "high-risk" group for FM, to clinically assess them and, if suspected, to refer them to clinical rheumatologists. Moreover, it is necessary to implement appropriate strategies and programs at the university level to identify, support and advise susceptible medical students.

Further research is necessary to clarify the etiology of FM, ascertain its association with factors such as stressors and vitamin D, and assess the impact of psychoeducational and behavior therapy in medical students suffering from FM.

The authors declare no conflicts of interests.

\section{References}

1. Sarzi-Puttini P, Giorgi V, Marotto D, Atzeni F. Fibromyalgia: an update on clinical characteristics, aetiopathogenesis and treatment. Nat Rev Rheumatol 2020; 16: 645-660, DOI: 10.1038/ s41584-020-00506-w.

2. Plesner KB, Vaegter HB. Symptoms of Fibromyalgia According to the 2016 Revised Fibromyalgia Criteria in Chronic Pain Patients Referred to Multidisciplinary Pain Rehabilitation: Influence on Clinical and Experimental Pain Sensitivity. J Pain 2018; 19: 777-786, DOI: 10.1016/j.jpain.2018.02.009.

3. Cabo-Meseguer A, Cerdá-Olmedo G, Trillo-Mata JL. Fibromyalgia: Prevalence, epidemiologic profiles and economic costs. Med Clínica Engl Ed 2017; 149: 441-448, DOI: 10.1016/j.medcle. 2017.10.011.

4. Marques AP, De Sousa A, Santo E, et al. Prevalence of fibromyalgia: literature review update. Rev Bras Reum Engl Ed 2017; 57: 356-363, DOI: 10.1016/j.rbre.2017.01.005.

5. Heidari F, Afshari M, Moosazadeh M. Prevalence of fibromyalgia in general population and patients: a systematic review and meta-analysis. Rheumatol Int 2017; 37: 1527-1539, DOI: 10.1007/s00296-017-3725-2.

6. Jones GT, Atzeni F, Beasley M, et al. The Prevalence of Fibromyalgia in the General Population: A Comparison of the American College of Rheumatology 1990, 2010, and Modified 2010 Classification Criteria. Arthritis Rheumatol 2015; 67: 568-575, DOI: 10.1002/art.38905.
7. Borchers AT, Gershwin ME. Fibromyalgia: A Critical and Comprehensive Review. Clin Rev Allergy Immunol 2015; 49: 100-151, DOI: 10.1007/s12016-015-8509-4.

8. Kivimäki $M$, Leino-Arjas P, Virtanen $M$, et al. Work stress and incidence of newly diagnosed fibromyalgia: Prospective cohort study. J Psychosom Res 2004; 57: 417-422, DOI: 10.1016/ j.jpsychores.2003.10.013.

9. Galvez-Sánchez CM, Duschek S, Del Paso GAR. Psychological impact of fibromyalgia: Current perspectives. Psychol Res Behav Manag 2019; 12: 117-127, DOI: 10.2147/PRBM.S178240.

10. Albrecht PJ, Rice FL. Fibromyalgia syndrome pathology and environmental influences on afflictions with medically unexplained symptoms. Rev Environ Health 2016; 31: 281-294, DOI: 10.1515/reveh-2015-0040.

11. Van Houdenhove B, Neerinckx E, Onghena P, et al. Daily Hassles Reported by Chronic Fatigue Syndrome and Fibromyalgia Patients in Tertiary Care: A Controlled Quantitative and Qualitative Study. Psychother Psychoso. 2002; 71: 207-213, DOI: 10.1159/000063646.

12. Pednekar DD, Amin MR, Fekri Azgomi H, et al. Characterization of Cortisol Dysregulation in Fibromyalgia and Chronic Fatigue Syndromes: A State-Space Approach. IEEE Trans Biomed Eng 2020; 67: 3163-3172, DOI: 10.1109/tbme.2020.2978801.

13. Barceló-Martinez E, Gelves-Ospina M, Navarro Lechuga E, et al. Serum cortisol levels and neuropsychological impairments in patients diagnosed with Fibromyalgia. Actas Esp Psiquiatr 2018; 46: 1-11.

14. Bergmann C, Muth T, Loerbroks A. Medical students' perceptions of stress due to academic studies and its interrelationships with other domains of life: a qualitative study. Med Educ Online 2019; 24, DOI: 10.1080/10872981.2019.1603526.

15. Vyas KS, Stratton TD, Soares NS. Sources of medical student stress. Educ Heal Chang Learn Pract 2017; 30: 232-235, DOI: 10.4103/efh.EfH_54_16.

16. Puthran R, Zhang MWB, Tam WW, Ho RC. Prevalence of depression amongst medical students: a meta-analysis. Med Educ 2016; 50: 456-468, DOI: 10.1111/medu.12962.

17. Almojali Al, Almalki SA, Alothman AS, et al. The prevalence and association of stress with sleep quality among medical students. J Epidemiol Glob Health 2017; 7: 169-174, DOI: 10.1016/j.jegh.2017.04.005.

18. Quek TTC, Tam WWS, Tran BX, et al. The global prevalence of anxiety among medical students: A meta-analysis. Int J Environ Res Public Health 2019; 16: 2735, DOI: 10.3390/ ijerph16152735.

19. Wolfe F, Clauw DJ, Fitzcharles MA, et al. 2016 Revisions to the 2010/2011 fibromyalgia diagnostic criteria. Semin Arthritis Rheum 2016; 46: 319-329, DOI: 10.1016/j.semarthrit.2016. 08.012 .

20. Wilson DMC, Nielsen E, Ciliska D. Lifestyle Assessment: Testing the FANTASTIC Instrument. Can Fam Phys 1984; 30: 1863-1866.

21. Wilhelm K, Handley T, Reddy P. Exploring the validity of the Fantastic Lifestyle Checklist in an inner city population of people presenting with suicidal behaviours. Aust N Z J Psychiatry 2016; 50: 128-134, DOI: 10.1177/0004867415621393.

22. Deluga A, Kosicka B, Dobrowolska B, et al. Lifestyle of the elderly living in rural and urbanareas measured by the fantastic 
life inventory. Ann Agric Environ Med 2018; 25: 562-567, DOI: 10.26444/aaem/86459.

23. Gansky SA, Plesh O. Widespread pain and fibromyalgia in a biracial cohort of young women. J Rheumatol 2007; 34: 810-817.

24. Felson DT. Comparing the prevalence of rheumatic diseases in China with the rest of the world. Arthritis Res Ther 2008; 10: 2-3, DOI: 10.1186/ar2369.

25. Toda K. The prevalence of fibromyalgia in Japanese workers. Scand J Rheumatol 2007; 36: 140-144, DOI: 10.1080/ 03009740600907949 .

26. Eyigor S, Ozdedeli S, Durmaz B. The prevalence of generalized soft tissue rheumatic conditions in Turkish medical students. J Clin Rheumatol 2008; 14: 65-68, DOI: 10.1097/ RHU.0b013e31816b1920.

27. Omair MA, Alobud S, Al-Bogami MH, et al. Prevalence of fibromyalgia in physicians in training: a cross-sectional study. Clin Rheumatol 2019; 38: 165-172, DOI: 10.1007/s10067-0184313-x.

28. Ge L, D'Souza RS, Oh T, et al. Tobacco Use in Fibromyalgia Is Associated With Cognitive Dysfunction. Mayo Clin Proc Innov Qual Outcomes 2019; 3: 78-85, DOI: 10.1016/j.mayocpiqo. 2018.12.002.

29. Kim CH, Vincent A, Clauw DJ, et al. Association between alcohol consumption and symptom severity and quality of life in patients with fibromyalgia. Arthritis Res Ther 2013; 15: R42, DOI: 10.1186/ar4200.

30. Conversano C, Poli A, Ciacchini R, et al. A psychoeducational intervention is a treatment for fibromyalgia syndrome. Clin Exp Rheumatol 2019; 37: 98-104.

31. Rockfeld J, Koppel J, Buell A, Zucconi R. An Interactive Lifestyle Medicine Curriculum for Third-Year Medical Students to Promote Student and Patient Wellness. MedEdPORTAL 2020; 16: 10972, DOI: 10.15766/mep_2374-8265.10972.

32. Noble H, Reid J, Walsh IK, et al. Evaluating mindfulness training for medical and PhD nursing students. Br J Nurs 2019; 28 : 798-802, DOI: 10.12968/bjon.2019.28.12.798.
33. De Vibe M, Solhaug I, Rosenvinge JH, et al. Six-year positive effects of a mindfulness-based intervention on mindfulness, coping and well-being in medical and psychology students; Results from a randomized controlled trial. PLoS One 2018; 13, DOI: 10.1371/journal.pone.0196053.

34. McLuckie A, Matheson KM, Landers AL, et al. The Relationship Between Psychological Distress and Perception of Emotional Support in Medical Students and Residents and Implications for Educational Institutions. Acad Psychiatry 2018; 42: 41-47, DOI: 10.1007/s40596-017-0800-7.

35. Domaradzki J, Walkowiak D. Medical students' knowledge and opinions about rare diseases: A case study from Poland. Intractable Rare Dis Res 2019; 8: 252-259, DOI: 10.5582/irdr. 2019.01099.

36. García-Ríos MC, Navarro-Ledesma S, Tapia-Haro RM, et al. Effectiveness of health education in patients with fibromyalgia: A systematic review. Eur J Phys Rehabil Med 2019; 55: 301-313, DOI: 10.23736/S1973-9087.19.05524-2.

37. Hill MR, Goicochea S, Merlo LJ. In their own words: stressors facing medical students in the millennial generation. Med Educ Online 2018; 23: 1530558, DOI: 10.1080/10872981.2018.1530558.

38. Slavin SJ, Chibnall JT. Finding the why, changing the how: Improving the mental health of medical students, residents, and physicians. Acad Med 2016; 91: 1194-1196, DOI: 10.1097/ ACM.0000000000001226.

39. Amarasuriya SD, Reavley NJ, Rossetto A, Jorm AF. Helping intentions of undergraduates towards their depressed peers: a cross-sectional study in Sri Lanka. BMC Psychiatry 2017; 17: 40, DOI: 10.1186/s12888-017-1192-7.

40. Heim E, Henderson C, Kohrt BA, et al. Reducing mental health-related stigma among medical and nursing students in low- and middle-income countries: A systematic review. Epidemiol Psychiatr Sci 2019; 20: e28, DOI: 10.1017/ S2045796019000167. 